\title{
MicroRNA-1-3p Suppresses Malignant Phenotypes of Ameloblastoma Through Down-Regulating Lysosomal Associated Membrane Protein 2-Mediated Autophagy
}

\author{
Xing Niu ${ }^{1,2+}$, Biying Huang ${ }^{2 \dagger}$, Xue Qiao ${ }^{3}$, Jinwen Liu ${ }^{2}$, Lijie Chen ${ }^{1,2}$ and Ming Zhong ${ }^{1,2 *}$ \\ ${ }^{1}$ Department of Stomatology, Xiang'an Hospital of Xiamen University, Xiamen, China, ${ }^{2}$ Department of Oral Histopathology, \\ Liaoning Province Key Laboratory of Oral Disease, School and Hospital of Stomatology, China Medical University, Shenyang, \\ China, ${ }^{3}$ Department of Central Laboratory, Liaoning Province Key Laboratory of Oral Disease, School and Hospital of \\ Stomatology, China Medical University, Shenyang, China
}

OPEN ACCESS

Edited by:

Fu Wang,

X'an Jiaotong University, China

Reviewed by:

Bo Liu,

Sichuan University, China

Jiqin Lian,

Third Military Medical University, China

*Correspondence:

Ming Zhong

zhongming_oral@aliyun.com

tThese authors have contributed equally to this work

Specialty section:

This article was submitted to Precision Medicine

a section of the journal

Frontiers in Medicine

Received: 20 February 2021 Accepted: 26 April 2021

Published: 26 May 2021

Citation:

Niu X, Huang B, Qiao X, Liu J, Chen L and Zhong $M$ (2021) MicroRNA-1-3p Suppresses Malignant Phenotypes of Ameloblastoma Through

Down-Regulating Lysosomal

Associated Membrane Protein 2-Mediated Autophagy.

Front. Med. 8:670188.

doi: 10.3389/fmed.2021.670188
Objective: Several clinical trials have suggested that autophagy inhibition is a promising approach for cancer therapy. However, the implications of autophagy in ameloblastoma (AB) remain undiscovered. This study investigated the dysregulated autophagy and its regulatory mechanisms in $\mathrm{AB}$.

Methods: The expression and distribution of autophagy-related proteins including B-cell lymphoma-2-interacting protein-1 (Beclin1), microtubule-associated protein 1 light chain 3 (LC3) II/I and lysosomal associated membrane protein 2 (LAMP2) were detected in $\mathrm{AB}$ and normal oral mucosa (NOM) tissues by immunohistochemistry and western blot analyses. Under transmission electron microscopy, the autophagy of $A B$ was observed. LAMP2 was a potential target mRNA of miR-1-3p. Quantitative Real-time PCR (qRT-PCR) analysis was utilized for examining LAMP2 and miR-1-3p in AB tissues as well as AM-1 cells. The correlation between LAMP2 and miR-1-3p was analyzed in $A B$. After transfection with miR-1-3p mimic or inhibitor, LAMP2 expression, proliferation, migration, and invasion were separately detected in AM-1 cells. Rescue assays were finally presented.

Results: Our results showed that Beclin1 was lowly expressed as well as LC3II// and LAMP2 were highly expressed in AB. Autophagosomes were observed in $A B$. MiR-1-3p was lowly expressed in $A B$, which exhibited negative correlations to LAMP2 expression. MiR-1-3p up-regulation significantly lowered LAMP2 expression in AM-1 cells. Furthermore, miR-1-3p overexpression restrained proliferative, migrated, and invasive capacities of AM-1 cells, which were ameliorated by LAMP2 overexpression.

Conclusion: Our findings demonstrated that miR-1-3p suppressed malignant phenotypes of AB through down-regulating LAMP2-mediated autophagy, which could become an underlying target for $\mathrm{AB}$ therapy.

Keywords: ameloblastoma, miR-1-3p, Beclin1, LAMP2, LC3, autophagy, malignant phenotypes 


\section{INTRODUCTION}

Ameloblastoma (AB), a common odontogenic epithelial neoplasm, exhibits locally invasive and aggressive behaviors (1). More than $80 \%$ of $\mathrm{AB}$ cases occur in the mandible (2). It has up to $90 \%$ risk of recurrence following conservative treatment (3). Although radical surgery can distinctly cut down the high recurrence risk, patients usually meet facial deformities (4). Unfortunately, the etiology of $\mathrm{AB}$ remains still unclear. Thus, it is of importance to research the molecular mechanisms of $A B$.

Autophagy is a stress response of eukaryotic cells to external pressure or stimulation such as starvation, hypoxia and toxicity (5). In the process of tumor development, autophagy may restrain the progression of tumors, but once the tumor is formed, autophagy may facilitate survival and growth of tumor cells (6). A previous study has found that LC-3 and p62 were highly expressed in primary AB-derived epithelial cells (7). Therefore, research on autophagy in odontogenic tumors is of great significance for understanding tumor occurrence and development. During autophagosome formation, microtubuleassociated protein 1 light chain 3 (LC3) can be transformed from LC3-I to LC3-II, and LC3-II binds to the newly formed autophagosome membrane until the final autophagosome fuses with the lysosome (8). Therefore, LC3-II has become a marker of intracellular autophagy. Lysosomal associated membrane protein 2 (LAMP2) is a member of the membrane glycoprotein family, which protects the lysosomal membrane from hydrolysis by acidic hydrolases, and regulates membrane fusion of lysosomes with other organelles during autophagy (9). Additionally, B-cell lymphoma-2-interacting protein-1 (Beclin1) exerts a critical role in a critical step of the autophagic process. However, there are few studies on the expressions and clinical implications of autophagyrelated proteins in $\mathrm{AB}$.

MicroRNAs (miRNAs), with 21-22 nucleotides in length, may mediate gene silencing at post-transcriptional levels $(10,11)$. In various tumors, abnormal expression of miRNAs is involved in various biological processes (12). The ability to regulate miRNA expression and activity in vivo by its mimic or inhibitor offers a direction for developing innovative treatment strategies against cancers. MiRNA-based therapies may provide higher stability as well as protection from nucleases (12). Several miRNA-targeted therapies against cancers have entered clinical trials such as miR-34 (12). However, it is a challenge about how to select the optimal candidate miRNAs for each disease. Many studies have demonstrated that miRNAs can play regulatory roles in the processes of autophagy by mediating target genes (1315). Among them, miR-1-3p is down-regulated in a variety of human tumors. For instance, overexpressed miR-1-3p restrains autophagy via targeting ATG3 in non-small cell lung cancer (16). Nevertheless, its expression and role in $\mathrm{AB}$ remain unclear.

\footnotetext{
Abbreviations: $\mathrm{AB}$, ameloblastoma; NOM, normal oral mucosa; LAMP2, lysosomal associated membrane protein 2; Beclin1, B-cell lymphoma-2-interacting protein-1; LC3, microtubule-associated protein 1 light chain 3; miRNA, microRNA; qRT-PCR, quantitative Real-time PCR; CCK-8, cell counting kit-8; EMT, epithelial-mesenchymal transition.
}

Herein, our research investigated abnormally expressed autophagy-related proteins and analyzed their clinical implications. Our findings suggested that autophagy imbalance could be involved in the progression of $\mathrm{AB}$. Furthermore, LAMP2 might become a potential target mRNA of miR-1-3p in $\mathrm{AB}$.

\section{MATERIALS AND METHODS}

\section{Tumor Specimens}

From 2014 to 2017, 12 paired $\mathrm{AB}$ and normal oral mucosa (NOM) fresh specimens were gathered from the oral and maxillofacial surgery of School and Hospital of Stomatology, China Medical University (Shenyang, China), which were then immediately stored at $-80^{\circ} \mathrm{C}$. Paraffin-embedded $104 \mathrm{AB}$ tissues and 20 NOM tissues were retrieved from the Department of Oral Histopathology, School and Hospital of Stomatology, China Medical University between 2015 and 2016. This research strictly followed the Declaration of Helsinki. Each patient signed written informed consent. Our research gained the approval of the Ethics Committee of School and Hospital of Stomatology, China Medical University (2016-12).

\section{Immunohistochemistry}

Paraffin-embedded tissue sections were cut to $100 \mu \mathrm{m}$ thick, dried, deparaffinized and rehydrated following standard protocols. The sections were incubated with primary antibodies against Beclin1 (1:500; ab622557; Abcam, Cambridge, MA, USA), LC3 (1:2,000; ab51520; Abcam) and LAMP2 (1:1,000; ab25631; Abcam) at $4^{\circ} \mathrm{C}$ overnight. Then, the sections were incubated with secondary antibodies for $30 \mathrm{~min}$ at room temperature. The sections were stained by diaminobenzidine (DAB; Thermo Fisher Scientific, Waltham, MA, USA). Nuclei were lightly stained with hematoxylin. For negative control, the sections were treated as above but PBS (Hyclone, South Logan, UT, USA) instead of primary antibodies.

For each section, three fields were randomly selected $(\times 200)$. The expression scores of Beclin1, LC3, and LAMP2 were on the grounds of staining intensity (no coloring: 0 point; light yellow: 1 point; brown yellow: 2 points; sepia: 3 points) and percentage of positive tumor cells ( $0-5 \%$ : 0 point; $6-25 \%$ : 1 point; $26-50 \%: 2$ points; $>50 \%: 3$ points) (17). The final score was determined by staining intensity score $\times$ percentage of positive tumor cells $(>4$ scores: positive and $0-3$ scores: negative).

\section{Western Blot}

Tissues were lysed using $300 \mu 1$ RIPA plus $3 \mu$ l protease inhibitor PMSF (Beyotime, Beijing, China) on the ice. After centrifugation for $5 \mathrm{~min}$ at $12,000 \times \mathrm{g}$, the supernatant was stored at $-20^{\circ} \mathrm{C}$. The protein concentration was determined using a BCA protein assay kit (Beyotime). Total proteins in the supernatant were subjected to separation in 10\% SDS-PAGE, followed by transference onto PVDF membranes (Millipore, USA). The membranes were blocked with 5\% skim milk powder lasting $1 \mathrm{~h}$ at room temperature. Afterwards, the membrane was incubated by primary antibodies at $4{ }^{\circ} \mathrm{C}$ overnight, and incubated with corresponding HRP-conjugated secondary antibodies (1:2,000; 
TABLE 1 | The primer information for qRT-PCR.

\begin{tabular}{ll}
\hline Target genes & Primer sequences (5'-3') \\
\hline LAMP2 & 5'-GTGAGTTGTATTGGGGTGATGTTA-3' (forward) \\
3-actin & 5'-CAATGATACTTGTCTGCTGGCTAC-3' (reverse) \\
& 5'-TGGCACCCAGCACAATGAA-3' (forward) \\
miR-1-3p & 5'-CTAAGTCATAGTCCGCCTAGAAGCA-3' (reverse) \\
& 5'-CCACGATGGAATGTAAAGAAGT-3' (forward) \\
ATG3 & 5'-CAGAGCAGGGTCCGAGGTA-3' (reverse) \\
& 5'-ACTGATGCTGGCGGTGAAGATG-3' (forward) \\
U6 & 5'-GTGCTCAACTGTAAAGGCTGCC-3' (reverse) \\
& 5'-ATTGGAACGATACAGAGAAGATT-3' (forward) \\
& 5'-GGAACGCTTCACGAATTG-3' (reverse) \\
\hline
\end{tabular}

Abcam) for $50 \mathrm{~min}$ at room temperature in the dark. The primary antibodies included anti-Beclin1 (1:2,000; ab622557; Abcam), anti-LC3 (1:1,000; ab51520; Abcam), anti-LAMP2 (1:500; ab25631; Abcam) and anti-GAPDH (1:8,000; ab9485; Abcam). GAPDH was used as an internal control. The protein blot was visualized using Odyssey CLx.

\section{Quantitative Real-Time PCR}

Total RNAs were extracted from tissues or cells with Trizol (Takara, Tokyo, Japan). For detection of miR-1-3p expression, cDNA was synthesized using TaqMan miRNA reverse transcription kit and specific primer of miR-1-3p. qRT-PCR was carried out on Hairpin-itTM Real-Time PCR Quantitation Kit. To detect the LAMP2 expression, cDNA synthesis was carried out using the SuperScript III. qRT-PCR quantification was performed using the SYBR Select Master Mix kit (Takara). $\beta$-actin and U6 served as internal controls of LAMP2 or miR$1-3 p$, respectively. The primer sequences of LAMP2, ATG3, $\beta$-actin, miR-1-3p, and U6 are shown in Table 1. LAMP2 and miR-1-3p expression was determined using $2^{-\Delta \Delta C T}$ method.

\section{Transmission Electron Microscope}

The tissues were washed using 0.1 cacodylate buffer $(\mathrm{pH}=7.4)$, which were then fixed with PBS solution plus 3\% glutaraldehyde as well as $2 \%$ paraformaldehyde. Standard protocols were presented for the rest of the process. The sections were stained with uranyl acetate and lead citrate. Images were captured under a transmission electron microscope.

\section{Cell Culture}

Human immortalized AM-1 cell line that was gifted by Iwate Medical University (Japan) were cultured in KeratinocyteSFM (Gibco, Invitrogen, USA). Human immortalized epidermal $\mathrm{HaCat}$ cell line that was purchased from Hunan Fenghui Biotechnology Co., Ltd. (Hunan, China) was cultured in DMEM (Hyclone, USA) containing $10 \% \mathrm{FBS}$ at $37^{\circ} \mathrm{C}, 5 \% \mathrm{CO}_{2}$.

\section{Transfection}

MiR-1-3p mimic, inhibitor and corresponding miR-negative control (miR-NC) as well as LAMP2 and control pcDNA3.1 were purchased from GenePharma (Shanghai, China). The sequences were as follows: miR-1-3p mimics: 5'-UGGAAUGU AAAGAAGUAUGUAU-3'; miR-1-3p inhibitors: 5'-AUACAUAC UUCUUUACAUUCCA-3'; miR-NC: 5'-UUCUCCGAACGU GUCACGUTT-3' or 5'-CAGUACUUUUGUGUAGUACAA-3'. AM-1 cells were seeded onto a 6-well plate for $24 \mathrm{~h}$. Hundred nanometer mimic, inhibitor, or miR-NC as well as $3 \mu \mathrm{g}$ plasmid were separately transfected into cells via Lipofectamine 2,000 reagent (Invitrogen, Carlsbad, CA, USA). Following transfection for $48 \mathrm{~h}$, cells were harvested.

\section{Dual Luciferase Reporter Assay}

The full or mutant fragments containing the predicted miR-1$3 p$ binding sites in LAMP2 3'-UTR were cloned into the firefly luciferase gene in GP-miRGLO vector (Promega, Fitchburg, WI, USA). Afterwards, AM-1 cells were co-transfected miR-1$3 p$ mimics or miR-NC with LAMP2 3'-UTR wild type (WT) or mutation (MUT). After $24 \mathrm{~h}$, relative luciferase activity was determined through the Dual-Luciferase Reporter assay system (Promega).

\section{Cell Counting Kit-8}

AM-1 cells were inoculated into a 96-well plate $\left(1 \times 10^{3}\right.$ cells/well). After transfection with miR-1-3p mimic, miR-1-3p inhibitor and miR-NC or treatment with $3 \mathrm{mmol} / \mathrm{L}$ autophagy inhibitor 3-MA, cells were measured at 0,24,48, 72, and $96 \mathrm{~h}$ using CCK-8 kit (Dojindo, Kumamoto, Japan). The absorbance value at $450 \mathrm{~nm}$ was determined with a microplate reader.

\section{Colony Formation Assay}

AM- 1 cells were inoculated in a $10 \mathrm{~cm}$ dish $\left(1 \times 10^{3}\right.$ cells $/$ dish $)$. Under culturing for 14 days, cells were fixed with methanol lasting $20 \mathrm{~min}$, followed by staining with $0.1 \%$ crystal violet.

\section{Flow Cytometry for Apoptosis}

AM-1 cells were inoculated onto a 6 -well plate $\left(4 \times 10^{4}\right.$ cells/well). Then, cells were centrifuged at 1,500 rpm for $5 \mathrm{~min}$. Following washing with PBS for three times, cells were treated by $5 \mu \mathrm{L}$ Annexin V-FITC as well as $5 \mu \mathrm{L}$ PI lasting $10 \mathrm{~min}$ at room temperature away from light. Cell apoptosis was detected through flow cytometry.

\section{Transwell Assay}

AM-1 cells $\left(4 \times 10^{4}\right.$ cells/well $)$ were inoculated onto the upper chamber in serum-free media with or without Matrigel. The lower chamber was added with culture medium. Under incubation lasting $24 \mathrm{~h}$, migrated or invasive cells to the lower chamber were immobilized using $4 \%$ paraformaldehyde as well as stained using hematoxylin and eosin.

\section{Statistical Analyses}

Statistical analyses were carried out utilizing Graphpad prism 7.0 and SPSS 17.0. Data are expressed as the mean \pm standard error of mean (SEM). All assays were repeated three times. Comparisons between groups were presented with student's $t$-test or one-way analysis of variance. Chi square test was used for comparing the associations between clinical parameters and expression of proteins. The correlation between miR-1-3p and 


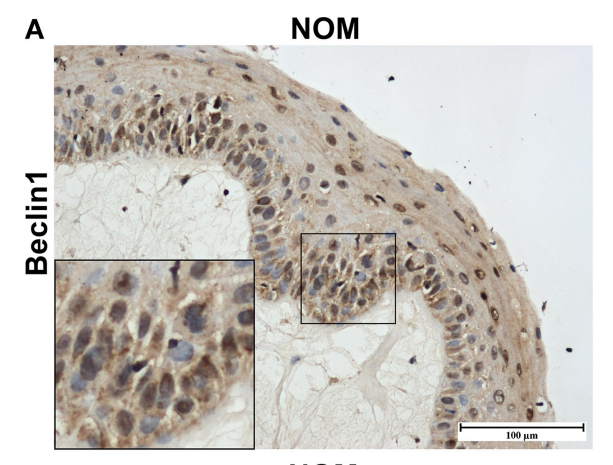

C

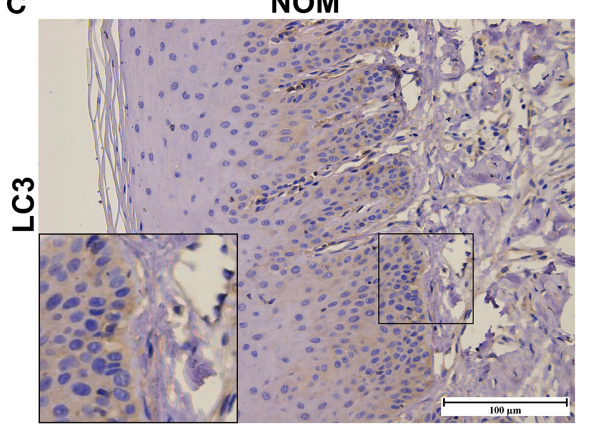

E

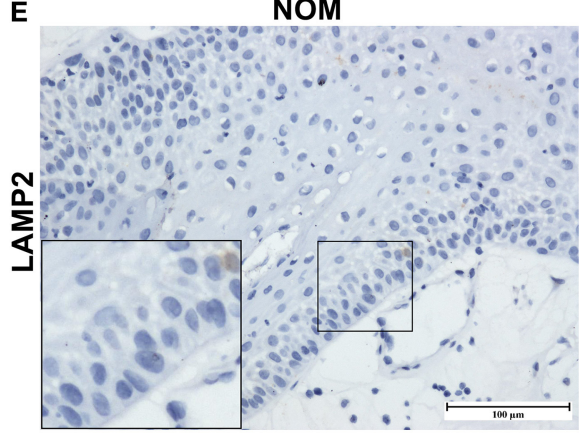

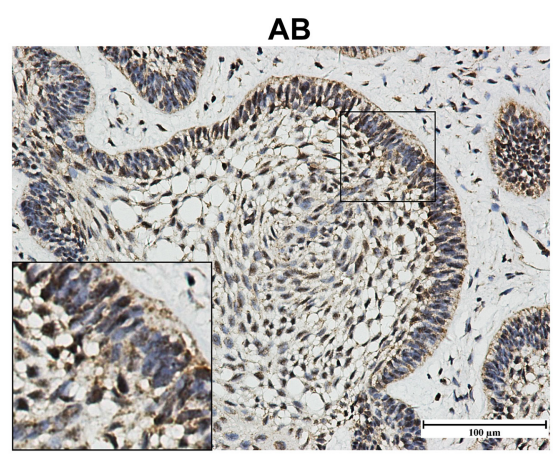

$A B$

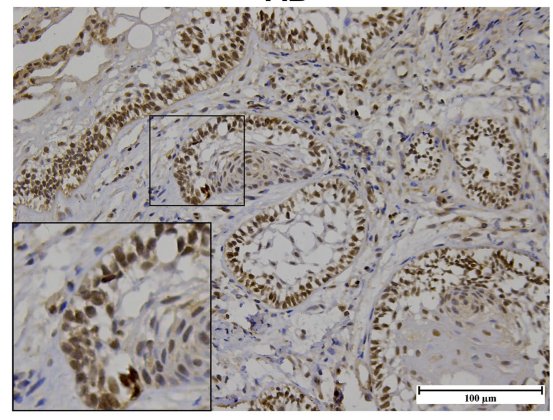

AB

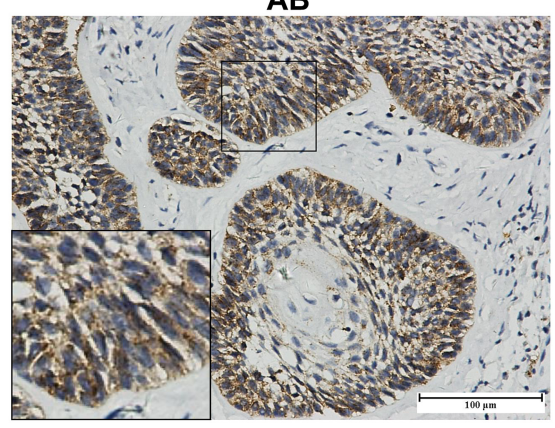

B

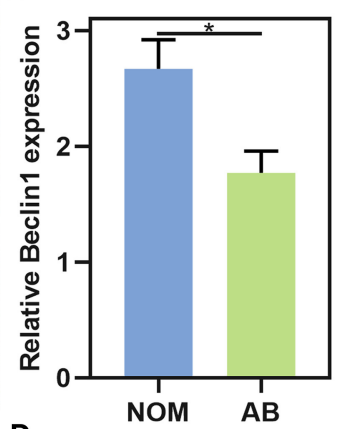

D
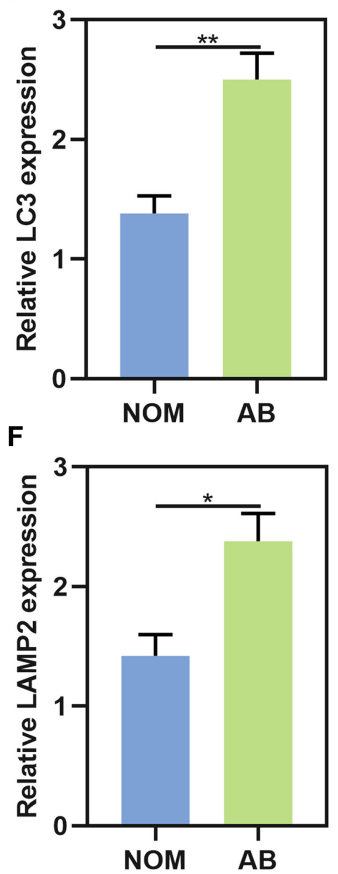

FIGURE 1 | The expression and distribution of Beclin1, LC3, and LAMP2 in AB and NOM tissues by immunohistochemistry. (A) Beclin1 is positively expressed in the nucleus of epithelial cells in NOM tissues and is positively expressed in the cytoplasm of epithelial cells in AB tissues. (B) Quantitative analysis results showing a lower expression level of Beclin1 in AB tissues than in NOM tissues. (C) $L C 3$ is negatively expressed in NOM and is positively expressed in the nuclei of epithelial cells in $A B$ tissues. (D) Quantitative analysis showing a higher expression level of LC3 in AB tissues than in NOM tissues. (E) LAMP2 is negatively expressed in NOM and is positively expressed in the cytoplasm and cell membrane of epithelial cells in AB tissues. (F) Quantitative analysis for a higher expression level of $L A M P 2$ in AB tissues than in NOM tissues. Bar: $100 \mu \mathrm{m}$. Magnification: 200x. ${ }^{*} P<0.05 ;{ }^{*} P<0.01$.

LAMP2 was evaluated via Spearman analysis. $P<0.05$ was indicative of statistical significance.

\section{RESULTS}

\section{The Expression and Distribution of Beclin1, LC3, and LAMP2 in AB and NOM Tissues}

This study included $104 \mathrm{AB}$ tissues and 20 NOM tissues. The expression and distribution of autophagy markers including Beclin1, LC3, and LAMP2 were assessed through immunohistochemistry. As shown in our results, Beclin1 was positively expressed in the nucleus of epithelial cells in NOM tissues (Figure 1A). Meanwhile, Beclin1 was positively expressed in the cytoplasm of epithelial cells in AB tissues. Quantitative analysis results confirmed that the expression of Beclin1 in NOM tissues was 1.51 times higher compared to that in $A B$ tissues $(P<0.05$; Figure 1B). The positive rate of Beclin1 expression in 104 cases of $\mathrm{AB}$ was 50\% (52/104), which was significantly lower than that in NOM tissues $(95 \%, 19 / 20)$. The correlations between Beclin1 expression and clinical pathological features were analyzed in AB. In Table 2, no significant difference was found between Beclin1 expression and age, gender, location, pathological classification, and recurrence of $\mathrm{AB}$ patients. In Figure 1C, LC3 was negatively expressed in NOM and the positive expression of LC3 was found in the nuclei of epithelial 
cells in $\mathrm{AB}$ tissues. $\mathrm{LC} 3$ expression in $\mathrm{AB}$ tissues was 1.82 times that of NOM tissues $(P<0.01$; Figure 1D). The positive expression rate of LC3 in 104 cases of AB was 76.92\% (80/104), which displayed a distinct higher level compared to that in NOM specimens $(10 \%, 2 / 20)$. But no significant difference was detected between the expression of LC3 and age, gender, and recurrence of $\mathrm{AB}$ patients (Table 3). Intriguingly, we found that the positive expression rate of LC3 in the mandible of $A B$ was significantly increased compared to that in the maxillary. Furthermore, the positive rate of LC3 in solid/multicystic AB exhibited a higher level in comparison to that in other types. In Figure 1E, LAMP2 was negatively expressed in NOM tissues while LAMP2 was primarily distributed in the cytoplasm and cell membrane of epithelial cells of AB. After quantification, LAMP2 expression in $\mathrm{AB}$ tissues was 1.68 times higher compared to that in NOM tissues $(P<0.05$; Figure $1 \mathbf{F})$. The positive expression rate of LAMP2 in 104 cases of AB was $63.46 \%(66 / 104)$, which was prominently more than that in $\mathrm{NOM}$ tissues $(5 \%, 1 / 20$; $P<0.05)$. In Table 4, LAMP2 expression in the mandible of $A B$ was significantly higher than that in the maxillary, indicating that LAMP2 expression might be related to $A B$ location. These findings indicated the dysregulated autophagy in $\mathrm{AB}$.

\section{Dysregulation of Autophagy in AB Tissues}

After immunohistochemistry, we further the expression levels of autophagy-related proteins including Beclin1, LC3II/I and LAMP2 in AB and NOM tissues by western blot. Consistent with immunohistochemistry results, western blot analysis demonstrated that Beclin1 expression in $A B$ tissues was distinctly lower compared to that in NOM specimens $(P<0.05$; Figures $2 \mathrm{~A}, \mathrm{~B})$. Furthermore, LC3II/I in $\mathrm{AB}$ tissues was significantly higher in comparison to that in NOM specimens $(P<0.01$; Figures 2 C,D $)$. As expected, overexpressed LAMP2 was detected in AB tissues in comparison to NOM specimens $(P<0.05$; Figures $2 \mathbf{E}, \mathbf{F})$. Ultrastructure of autophagosomes was investigated in $\mathrm{AB}$ tissues under a transmission electron microscopy (Figure 3). Above findings demonstrated the autophagy activation in $\mathrm{AB}$.

\section{LAMP2 Is a Target mRNA of miR-1-3p in AB}

Previous studies have highlighted the roles of miR-1-3p in cancers. Bioinformatics analysis showed that miR-1-3p could bind to 3'UTR of LAMP2 mRNA among three autophagy-related proteins. We firstly analyzed the expression levels of miR-1-3p and LAMP2 in AB tissues by qRT-PCR. As a result, miR-1$3 \mathrm{p}$ was distinctly lowly expressed in $\mathrm{AB}$ than NOM tissues $(P$ $<0.001$; Figure 4A). On the contrary, LAMP2 mRNA in AB tissues displayed a higher level in comparison to NOM tissues $(P<0.01$; Figure 4B). Spearman correlation analysis results suggested that miR-1-3p expression was negatively correlated with LAMP2 expression in AB tissues $(r=-0.8881, P=0.0003$; Figure 4C). These data were indicative that LAMP2 might be a target mRNA of miR-1-3p in AB. MiR-1-3p expression was further detected in AM-1 and HaCat cells. Our results showed the down-regulation of miR-1-3p in AM-1 cells compared to
HaCat cells $(P<0.01$; Figure 4D). In Figure 4E, miR-1-3p was mainly expressed in extracellular, mitochondrion, nucleus, and cytosol. LAMP2 mRNA was significantly up-regulated in AM-1 cells compared to HaCat cells $(P<0.01$; Figure 4F). MiRNAs mediate the silencing of target genes at the posttranscriptional level by binding to the 3'-untranslated region (3'-UTR) of mRNAs. By the miRanda database (http://www. miranda.org/), we found that LAMP2 was a potential target of miR-1-3p (Figure 4G). Luciferase assay confirmed that miR1-3p may bind to LAMP2, and inhibited LAMP2 luciferase activity in AM-1 cells $(P<0.0001$; Figure 4G). However, no inhibitory effect was found after mutation of this binding motif. To confirm whether miR-1-3p affected LAMP2 expression, miR1-3p mimic or inhibitor was transfected into AM-1 cells. In Figure $4 \mathbf{H}$, it was successfully overexpressed by miR-1-3p mimic transfection $(P<0.0001)$ while it was silenced after transfection with miR-1-3p inhibitor $(P<0.05)$. As expected, LAMP2 protein expression was decreased by miR-1-3p mimic $(P<0.001)$ and increased by its inhibitor $(P<0.01$; Figure 4I). Similarly, miR1-3p mimic significantly lowered the expression of LAMP2 mRNA in AM-1 cells $(P<0.01$; Figure 4J). Meanwhile, LAMP2 expression was distinctly up-regulated when transfected by miR$1-3 p$ inhibitor $(P<0.001)$. A previous study reported that ATG3 was a potential target of miR-1 in NSCLC cells (16). However, our data showed that miR-1-3p mimic or inhibitor did not significantly alter ATG3 expression in AM-1 cells (Figure 4K).

\section{miR-1-3p Restrains Proliferation and Facilitates Apoptosis in AB Cells}

Firstly, we observed the roles of autophagy on malignant phenotypes of AB. After AM-1 cells were treated with $3 \mathrm{mmol} / \mathrm{L}$ autophagy inhibitor 3-MA for $0,24,48,72$, and $96 \mathrm{~h}$, cell viability was measured. As a result, 3-MA treatment distinctly suppressed cell proliferation ( $p<0.05$; Figure 5A), indicating that inhibiting autophagy could weaken malignant progression of $\mathrm{AB}$. Then, the functions of miR-1-3p on $\mathrm{AB}$ progression were investigated in depth. As a result, its overexpression lowered the cell viability of AM-1 cells $(P<0.0001)$. Meanwhile, the cell viability of AM-1 cells was increased by its knockdown $(P<0.0001$; Figure 5B). Clone formation ability was further evaluated. In Figures 5C,D, miR-1-3p mimic significantly decreased the number of clones $(P<0.01)$ and the opposite results were observed when transfected by miR-1-3p inhibitor $(P<0.001)$. Furthermore, AM-1 cells displayed elevated apoptotic levels following transfection by miR-1-3p mimic $(P$ $<0.001$; Figures 5E,F). However, its inhibitor decreased the apoptosis of AM-1 cells $(P<0.01)$. Collectively, miR-1-3p may restrain proliferation as well as facilitate apoptosis in AM1 cells.

\section{miR-1-3p Reduces Migrated and Invasive Capacities in AB Cells}

This study further evaluated migration and invasion of $\mathrm{AB}$ cells by transwell assays. As a result, the number of migrated AM-1 cells was markedly reduced by miR-1-3p 
TABLE 2 | The association of Beclin1 expression with clinical pathological characteristics of AB.

\begin{tabular}{|c|c|c|c|c|c|}
\hline Clinical pathological characteristics & & Cases & Beclin1 expression ( $n, \%)$ & $x^{2}$ & $\boldsymbol{P}$ \\
\hline \multirow[t]{2}{*}{ Age } & $>50$ & 31 & $17(54.84)$ & 0.414 & 0.520 \\
\hline & $\leq 50$ & 73 & 35 (47.95) & & \\
\hline \multirow[t]{2}{*}{ Sex } & Male & 60 & $27(45.00)$ & 1.418 & 0.234 \\
\hline & Female & 44 & $25(56.82)$ & & \\
\hline \multirow[t]{2}{*}{ Location } & Mandible & 84 & $43(51.19)$ & 0.248 & 0.619 \\
\hline & Maxillary & 20 & $9(45.00)$ & & \\
\hline \multirow[t]{4}{*}{ Classification } & Solid/multicystic & 83 & 39 (46.99) & 1.492 & 0.506 \\
\hline & Unicystic & 12 & $13(61.90)$ & & \\
\hline & Peripheral & 6 & & & \\
\hline & Desmoplastic & 3 & & & \\
\hline \multirow[t]{2}{*}{ Recurrence } & Yes & 10 & $4(40.00)$ & 0.443 & 0.506 \\
\hline & No & 94 & $48(51.06)$ & & \\
\hline
\end{tabular}

TABLE 3 | The association of LC3 expression with clinical pathological characteristics of AB.

\begin{tabular}{|c|c|c|c|c|c|}
\hline Clinical pathological characteristics & & Cases & LC3 expression $(n, \%)$ & $x^{2}$ & $P$ \\
\hline \multirow[t]{2}{*}{ Age } & $>50$ & 31 & $23(74.19)$ & 0.185 & 0.667 \\
\hline & $\leq 50$ & 73 & 57 (78.08) & & \\
\hline \multirow[t]{2}{*}{ Sex } & Male & 60 & 46 (76.67) & 0.005 & 0.942 \\
\hline & Female & 44 & $34(77.27)$ & & \\
\hline \multirow[t]{2}{*}{ Location } & Mandible & 84 & 70 (83.33) & 8.321 & $0.004^{* *}$ \\
\hline & Maxillary & 20 & $10(50.00)$ & & \\
\hline \multirow[t]{4}{*}{ Classification } & Solid/multicystic & 83 & 68 (81.93) & 4.487 & $0.034^{*}$ \\
\hline & Unicystic & 12 & $12(57.14)$ & & \\
\hline & Peripheral & 6 & & & \\
\hline & Desmoplastic & 3 & & & \\
\hline \multirow[t]{2}{*}{ Recurrence } & Yes & 10 & $8(80.00)$ & $<0.001$ & 1.000 \\
\hline & No & 94 & $72(76.60)$ & & \\
\hline
\end{tabular}

${ }^{\star} P<0.05 ;{ }^{* \star} P<0.01$.

TABLE 4 | The association of LAMP2 expression with clinical pathological characteristics of AB.

\begin{tabular}{|c|c|c|c|c|c|}
\hline Clinical pathological characteristics & & Cases & LAMP2 expression ( $n, \%)$ & $x^{2}$ & $\boldsymbol{P}$ \\
\hline \multirow[t]{2}{*}{ Age } & $>50$ & 31 & $16(51.61)$ & 2.674 & 0.102 \\
\hline & $\leq 50$ & 73 & 50 (68.49) & & \\
\hline \multirow[t]{2}{*}{ Sex } & Male & 60 & $36(60.00)$ & 0.733 & 0.392 \\
\hline & Female & 44 & $30(68.18)$ & & \\
\hline \multirow[t]{2}{*}{ Location } & Mandible & 84 & $60(71.43)$ & 11.957 & $0.001^{\star \star \star}$ \\
\hline & Maxillary & 20 & $6(30.00)$ & & \\
\hline \multirow[t]{4}{*}{ Classification } & Solid/multicystic & 83 & 52 (62.65) & 0.117 & 0.733 \\
\hline & Unicystic & 12 & $14(66.67)$ & & \\
\hline & Peripheral & 6 & & & \\
\hline & Desmoplastic & 3 & & & \\
\hline \multirow[t]{2}{*}{ Recurrence } & Yes & 10 & $6(80.00)$ & $<0.001$ & 1.000 \\
\hline & No & 94 & $60(63.83)$ & & \\
\hline
\end{tabular}

${ }^{* \star \star} P<0.001$ 


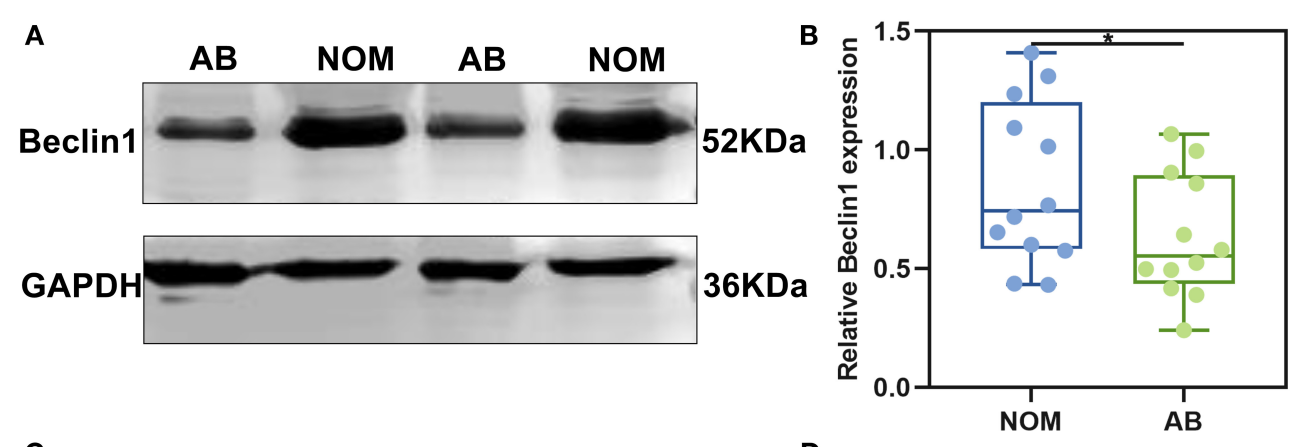

C

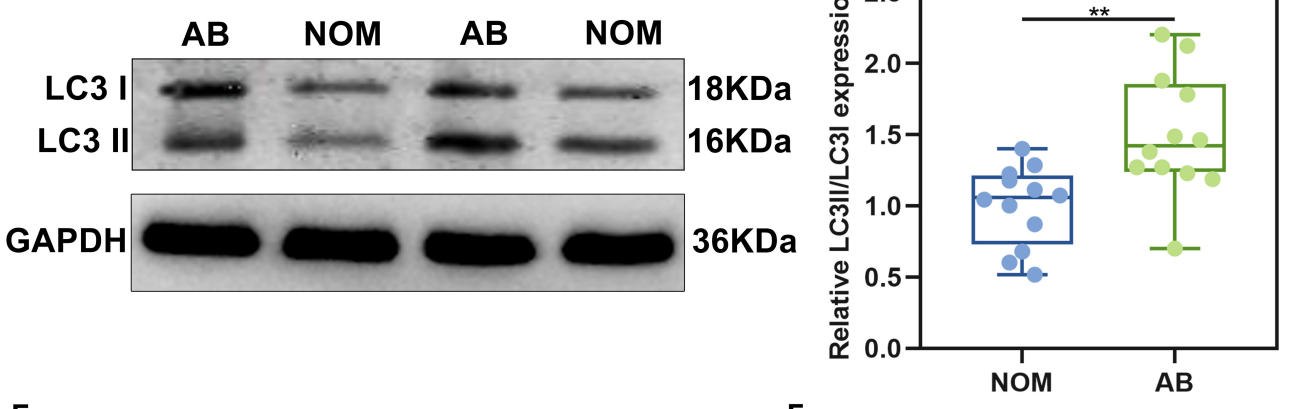

E

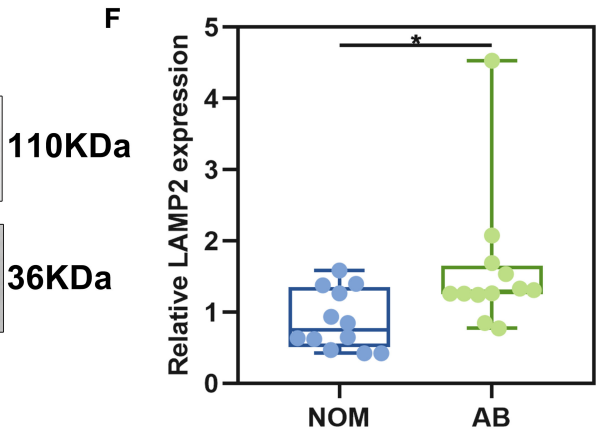

FIGURE 2 | The expression of autophagy-related proteins Beclin1, LC3II/I, and LAMP2 in AB and NOM tissues by western blot. (A,B) Beclin1; (C,D) LC3II/I; (E,F) LAMP2. ${ }^{*} P<0.05 ;{ }^{* \star} P<0.01$.

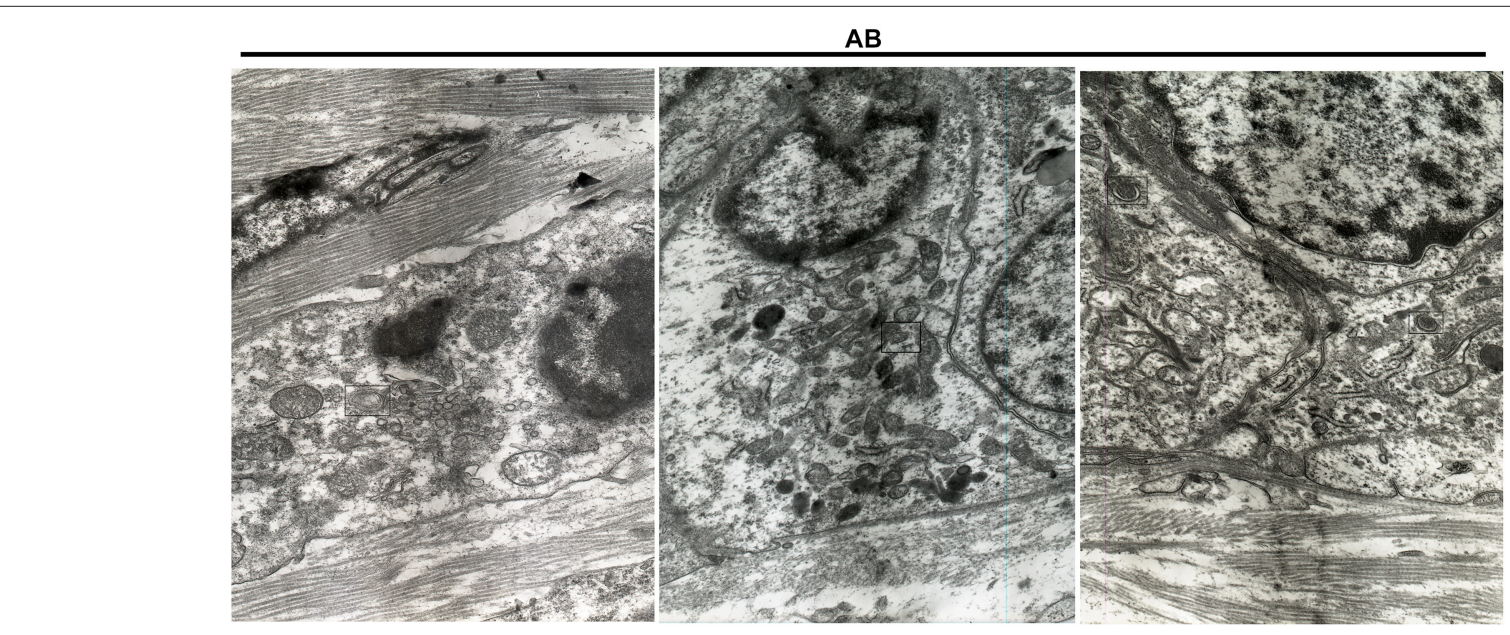

FIGURE 3 | Transmission electron microscopy for the structure of autophagosomes in AB. The autophagosomes are marked. 

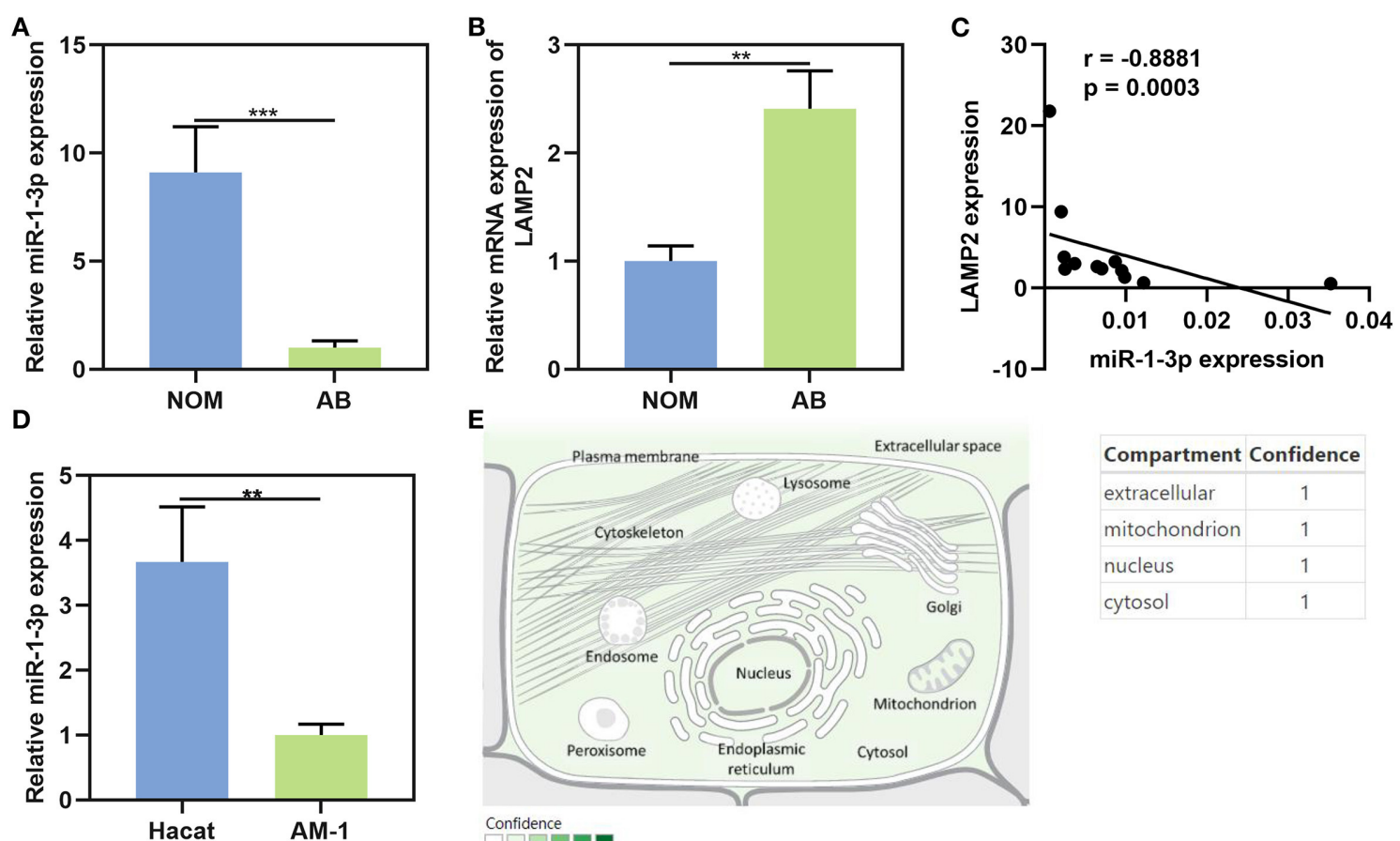

E

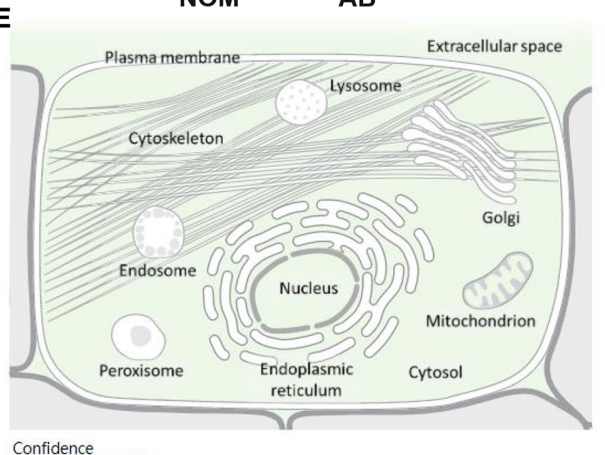

\section{Compartment Confidence}

extracellular

mitochondrion

nucleus

cytosol

\section{$\begin{array}{llllll}0 & 1 & 2 & 3 & 4 & 5\end{array}$}
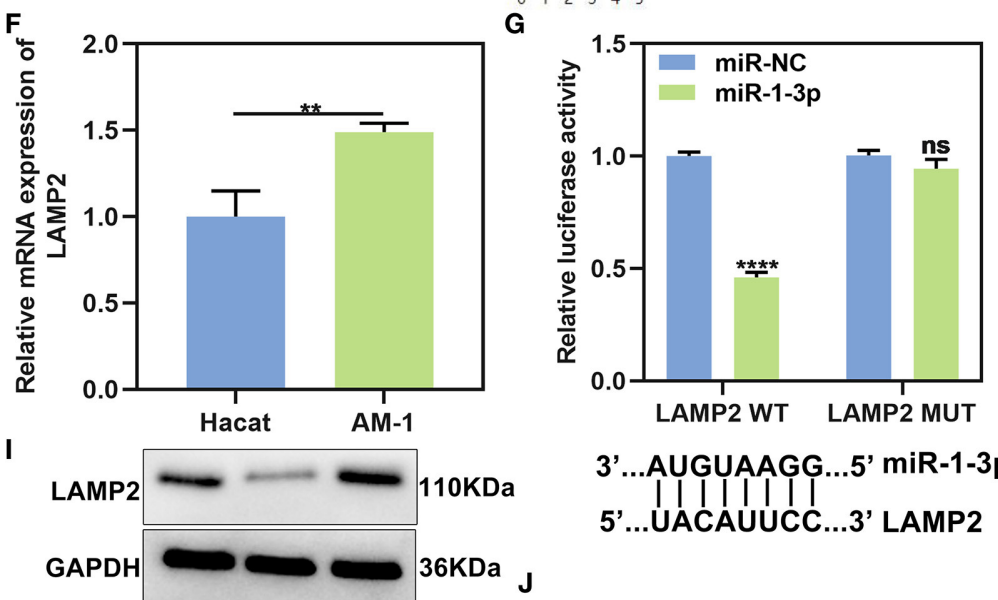

H

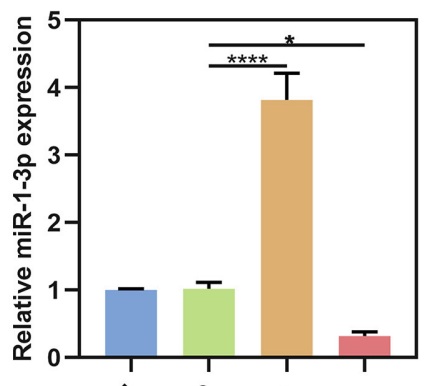

3'...AUGUAAGG...5' miR-1-3p 5'...UACAUUUCC...3' LAMP2
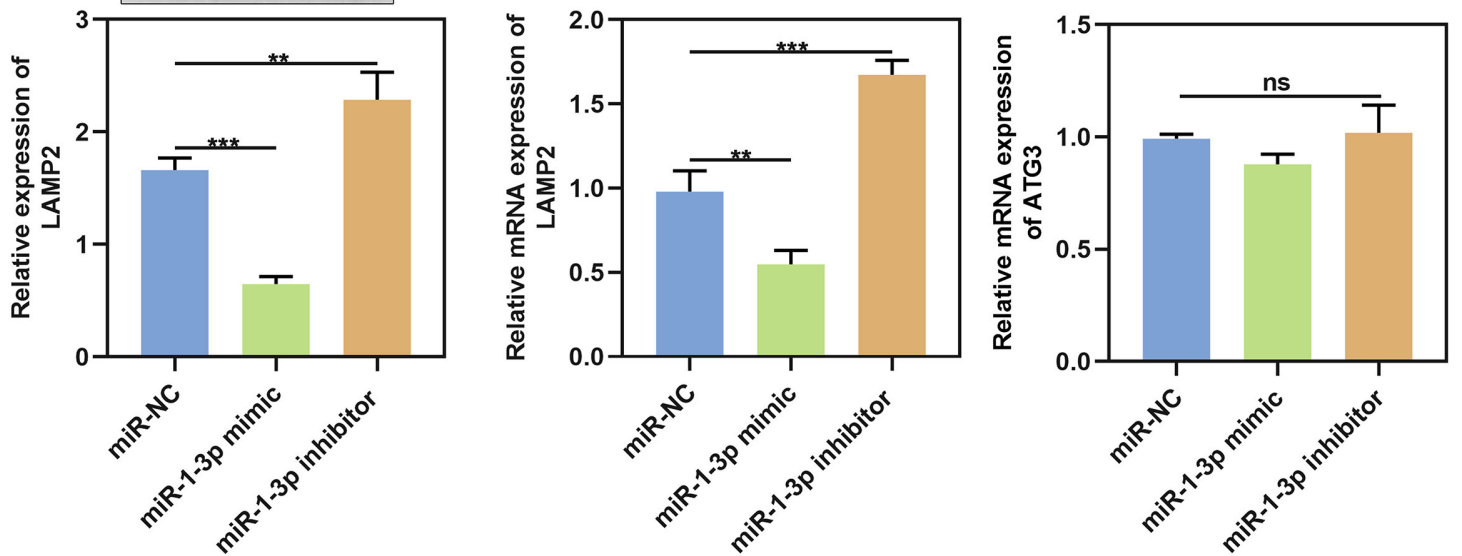

FIGURE 4 | MiR-1-3p suppresses LAMP2 expression in AB. (A,B) qRT-PCR for the expression of miR-1-3p and LAMP2 in NOM and AB tissues. (C) Spearman correlation analysis of miR-1-3p expression and LAMP2 expression in AB tissues $(r=-0.8881, P=0.0003)$. (D) qRT-PCR for the expression of miR-1-3p in AM-1 
FIGURE 4 | cells and HaCat cells. (E) The distribution of miR-1-3p in cells. (F) qRT-PCR for the expression of LAMP2 in AM-1 cells and HaCat cells. (G) Assessment of relative luciferase activity in AM-1 cells after transfection with miR-1-3p mimic or miR-NC and schematic representation of the predicted miR-1-3p target sites within the 3'-UTR of LAMP2. (H) Assessment of the expression of miR-1-3p in AM-1 cells transfected with its mimic or inhibitor. (I) Western blot for LAMP2 expression in AM-1 cells transfected with miR-1-3p mimic or inhibitor. ( $\mathbf{J}$ ) qRT-PCR for detecting LAMP2 expression in AM-1 cells under transfection with miR-1-3p mimic or inhibitor. (K) qRT-PCR for examining ATG3 expression in AM-1 cells transfected with miR-1-3p mimic or inhibitor. ${ }^{*} P<0.05 ;{ }^{* \star} P<0.01 ;{ }^{* \star \star} P<0.001 ;{ }^{* \star \star \star} P<$ 0.0001; ns, not significant.
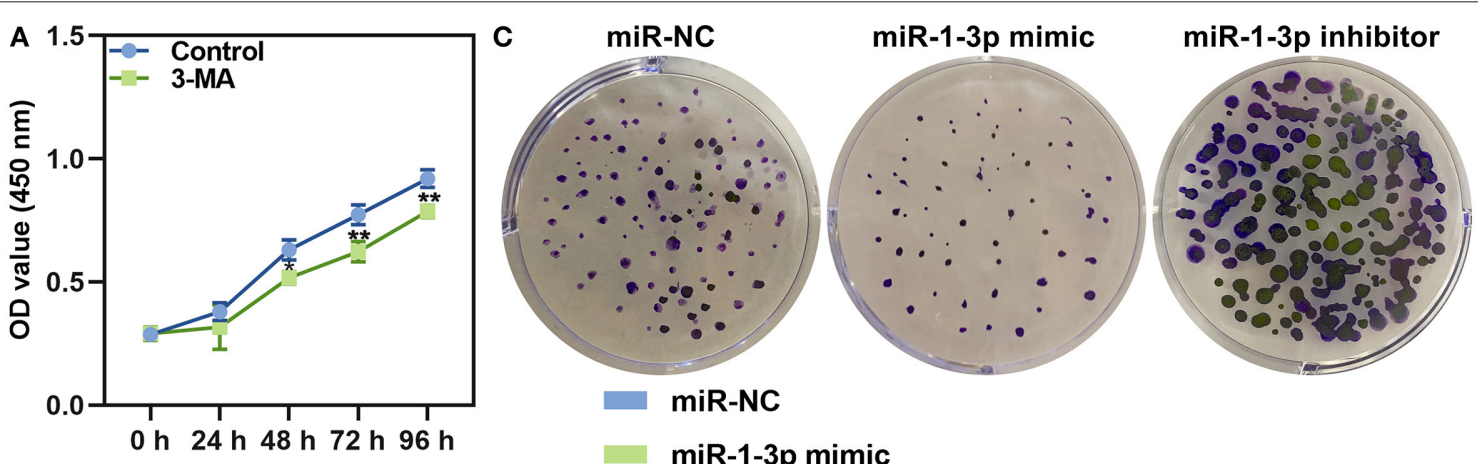

B

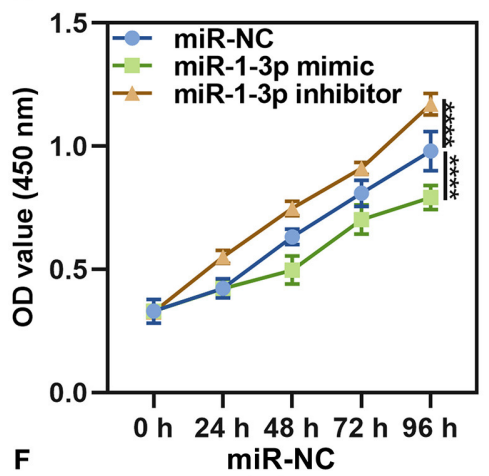

D

\section{miR-1-3p mimic}
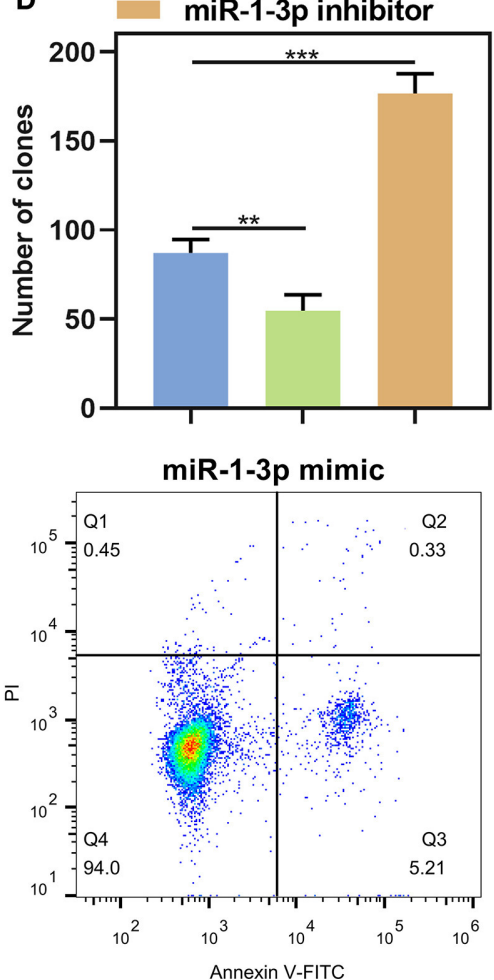

E
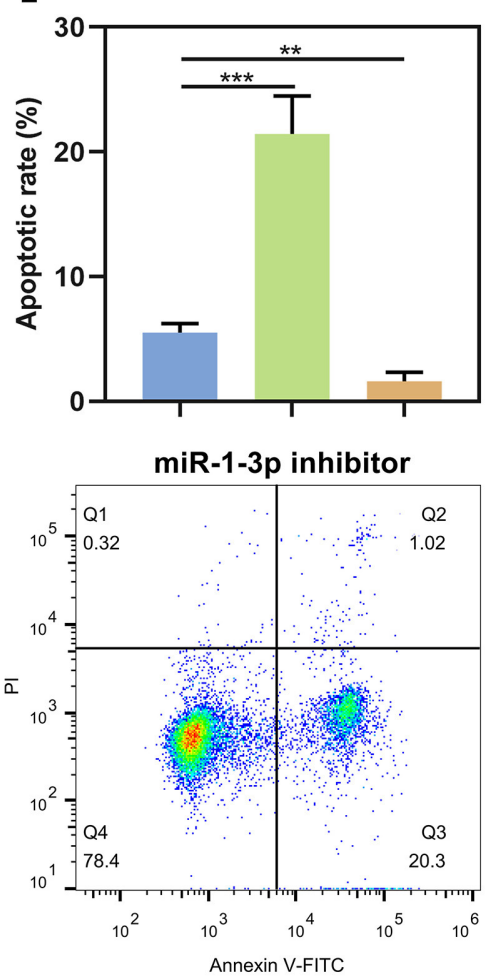

FIGURE 5 | The roles of miR-1-3p on proliferation and apoptosis in AM-1 cells. (A) CCK-8 for cell viability of AM-1 cells treated with autophagy inhibitor 3-MA at 0 , 24, 48, 72, and $96 \mathrm{~h}$. (B) CCK-8 for cell viability of AM-1 cells transfected with miR-1-3p mimic or inhibitor at 0, 24, 48, 72, and 96 h. (C,D) The number of colonies of AM-1 cells with miR-1-3p mimic or inhibitor transfection. (E,F) Flow cytometry for detecting apoptosis of transfected AM-1 cells. ${ }^{\star} P<0.05 ;{ }^{* \star} P<0.01 ;{ }^{* \star *} P<0.001$; ${ }^{\star \star \star \star *} P<0.0001$.

mimic $(P<0.001)$, which was increased after transfection by its inhibitor $(P<0.001$; Figures 6A,B). Furthermore, its knockdown restrained invasive capacities of AM-1 cells $(P<0.01)$ and the opposite consequences were investigated after overexpressing miR-1-3p $(P<0.001$; Figures 6C,D). 

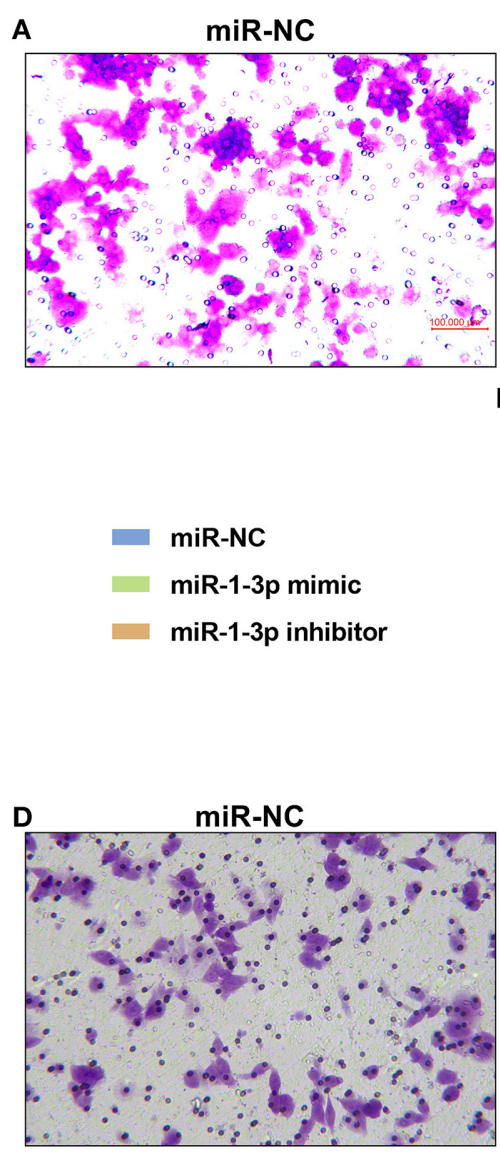
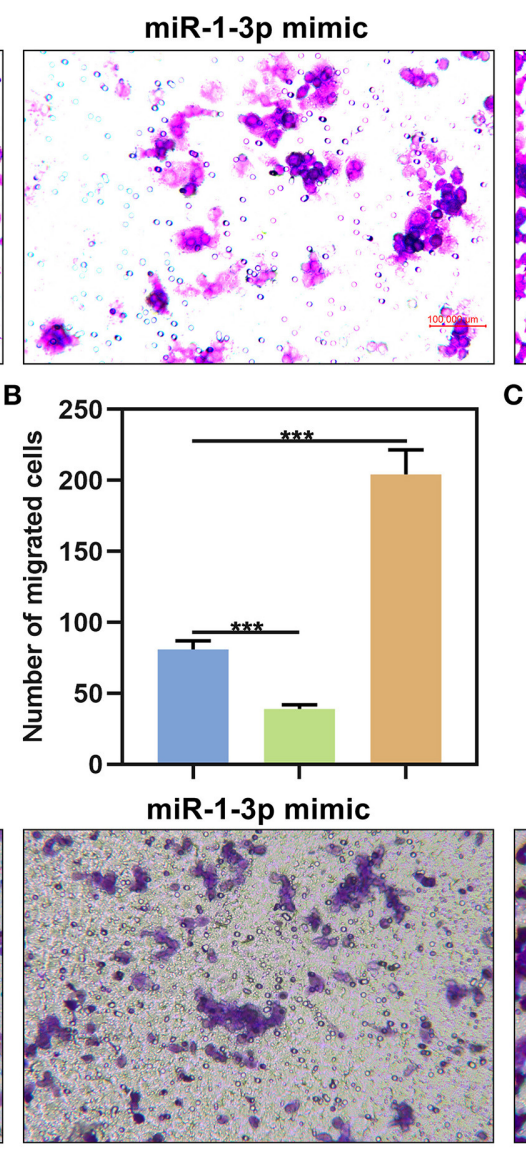
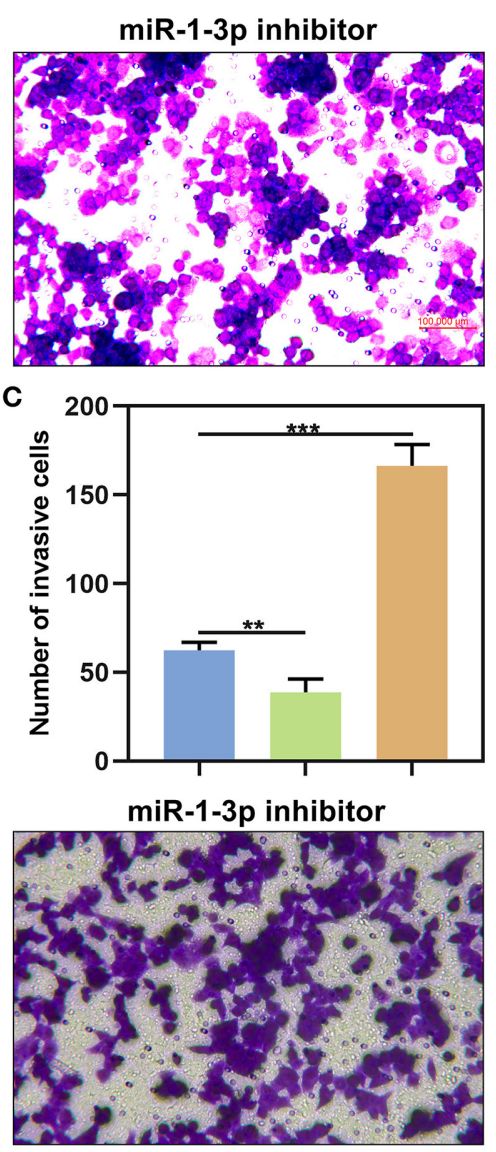

FIGURE 6 | The effects of miR-1-3p on migration and invasion of in AM-1 cells. (A,B) Evaluation of the number of migrated AM-1 cells transfected with miR-1-3p mimic or inhibitor. (C,D) Detection of the number of invasive AM-1 cells after transfection. ${ }^{* \star} P<0.01 ;{ }^{\star \star \star} P<0.001$.

\section{miR-1-3p Suppresses Malignant Phenotypes of AB Cells by Down-Regulating LAMP2}

LAMP2 was significantly overexpressed in AM-1 cells under transfection with pcDNA3.1 LAMP2 $(P<0.001$; Figure 7A). The up-regulation significantly increased the number of clones of AM-1 cells $(P<0.0001$; Figures 7B,C). Furthermore, the decrease in the number of clones induced by miR-1-3p overexpression was markedly ameliorated by LAMP2 upreg ulation $(P<0.01)$. We also found that LAMP2 overexpression distinctly enhanced migrated $(P<0.0001$; Figures 7D,E) and invasive $(P<0.0001$; Figures 7F,G) abilities of AM-1 cells. Meanwhile, its up-regulation ameliorated the reduction in migrated $(P<0.0001)$ and invasive $(P<0.0001)$ abilities of AM-1 cells induced by miR-1-3p mimic. Above findings were indicative that miR-1-3p suppressed malignant phenotypes of $A B$ cells by down-regulating LAMP2.

\section{DISCUSSION}

Here, our research analyzed the dysregulated expression and clinical implications of autophagy-related proteins including
Beclin1, LC3II/I, and LAMP2 in AB. Also, we found that LAMP2 might be a potential target mRNA of miR-1-3p in $A B$. This miRNA may suppress malignant phenotypes of $A B$ cells by down-regulating LAMP2.

Studies have shown that epithelial cells of $A B$ have stronger autophagy activity than mesenchymal cells, human odontogenic cells, and maxillary mesenchymal stem cells, indicating that autophagy may promote the cell viability of residual $\mathrm{AB}$ epithelial cells in the hypoxic tumor microenvironment that is in relation to local invasion of $\mathrm{AB}$ (7). Consistently, our data showed that inhibiting autophagy significantly weakened cell proliferation of AM-1 cells. BRAF mutation often occurs in AB and is associated with recurrence of $\mathrm{AB}(18,19)$. It has been found that BRAF oncogene induces the expression of key autophagy markers including LC3 and Beclin1, suggesting that the recurrence of $A B$ might be due to the activation of autophagy of residual $A B$ cells after surgery (20). However, in this study, we found that there was no correlation between LC3 or Beclin1 expression and AB recurrence, which requires in-depth research.

Epithelial-mesenchymal transition (EMT) is a key process in the invasion as well as metastases of $\mathrm{AB}(21)$. Adherent epithelial cells into highly active mesenchymal cells are the early stage of tumor invasion and metastasis. For example, in liver cancer, 

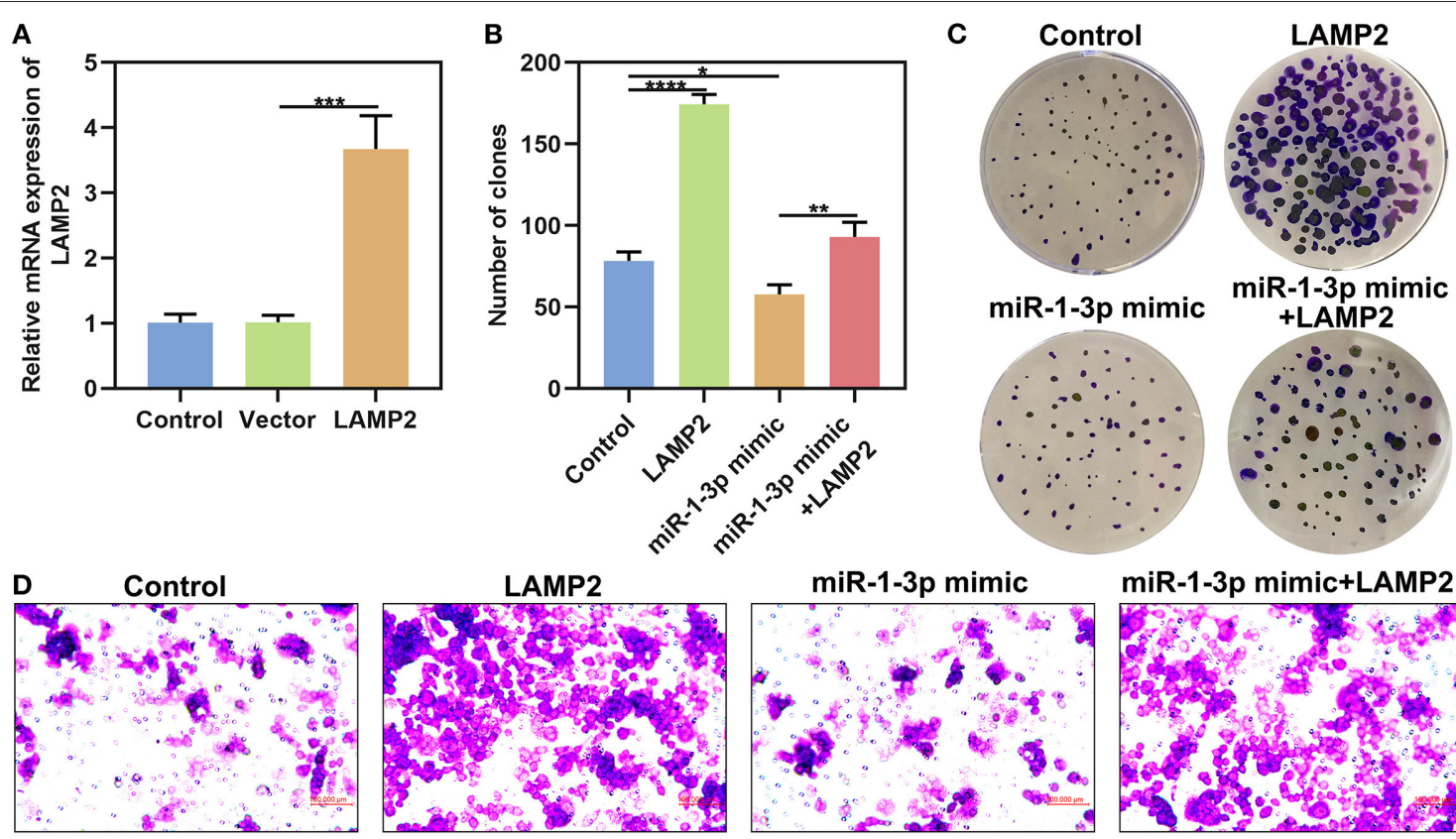

miR-1-3p mimic

miR-1-3p mimic+LAMP2
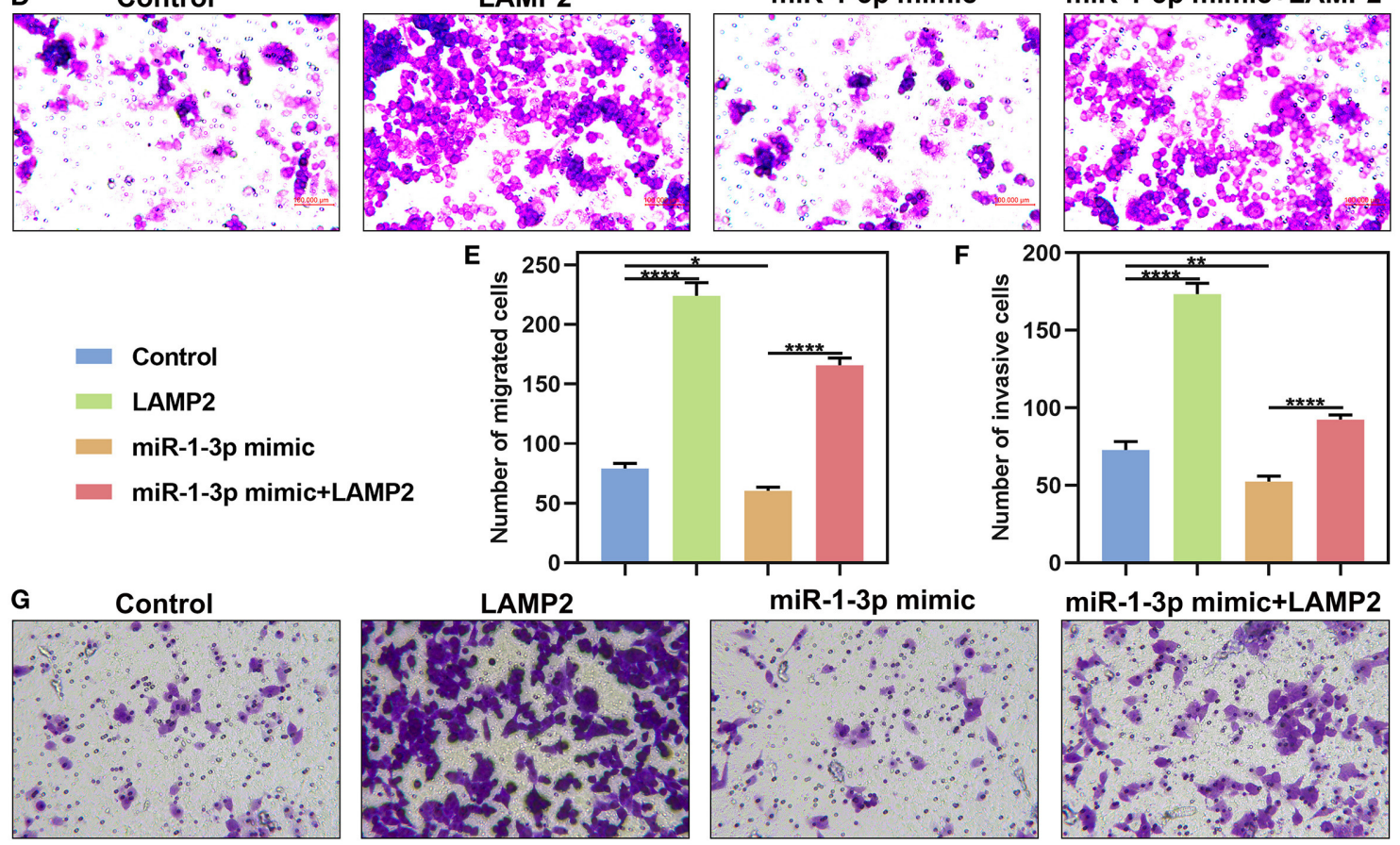

FIGURE 7 | miR-1-3p suppresses colony formation, migration and invasion of AM-1 cells by down-regulating LAMP2. (A) qRT-PCR for evaluating the expression of LAMP2 in AM-1 cells with pcDNA3.1 LAMP2 plasmid transfection. (B,C) The number of colonies for AM-1 cells transfected with LAMP2 and/or miR-1-3p mimic. (D-G) The number of (D,E) migrated and (F,G) invasive AM-1 cells under transfection with LAMP2 and/or miR-1-3p mimic. ${ }^{*} P<0.05 ;{ }^{* *} P<0.01 ;{ }^{* \star *} P<0.001$; ${ }^{\star * \star \star} P<0.0001$.

starvation-induced autophagy promotes the expression of EMTrelated molecular markers through the transforming growth factor $\beta$ (TGF- $\beta$ )/Smad3 signaling pathway, thereby enhancing the invasive ability of hepatoma cells (22). In bladder cancer, it has been also demonstrated that autophagy can activate TGF$\beta /$ Smad signaling pathway-mediated EMT to promote tumor cell invasion and metastasis (23). At present, it has been found that EMT-related transcription factors Slug, Snail and TGF- $\beta$ are upregulated and E-cadherin expression is down-regulated in $A B$ tissues, suggesting EMT may be involved in the development of $\mathrm{AB}$ (24). In this study, western blot analysis results showed that in $\mathrm{AB}$ tissues, Beclin1 expression was down-regulated, while LC3 and LAMP2 were both up-regulated, indicating that autophagy was activated in $\mathrm{AB}$. Combining previous studies, autophagy might increase the invasive ability of $\mathrm{AB}$ cells via promoting EMT process.

As shown in immunohistochemistry, the positive expression rate of LC3 and LAMP2 in the mandible of AB was significantly elevated compared to that in the maxilla. Because the incidence rate of $\mathrm{AB}$ in the mandible is significantly higher than that in the maxilla. Moreover, there is no report on the relationships between $\mathrm{AB}$ location and tumor biological behaviors. It is difficult to prove that the expression levels of LAMP2 and LC3 are in association with $\mathrm{AB}$ location (25). We speculate that in the 
mandible, blood supply is more singular, the bone is denser, and the tumor cells are more prone to hypoxia or energy deficiency compared to the maxilla, however, autophagy can supply energy for tumor cell proliferation. In this study, the cases of the $\mathrm{AB}$ occurring in the maxilla was small and the differences between the positive expression rates of LC 3 and LAMP2 and AB location still need to be further validated in a larger cohort. In addition, the positive expression rate of LC3 in solid/polycystic AB was significantly higher than other classifications. It has been found that the recurrence rate of solid/polycystic $A B$ is significantly higher than other classifications, suggesting that elevated levels of autophagy in solid/polycystic AB may be associated with tumor recurrence (26).

Currently, the molecular biology research on $\mathrm{AB}$ focuses on finding biomarkers. Combining with our previous human miRNA expression microarray results (six pairs of $A B$ vs. NOM), among the down-regulated miRNAs, miR-1-3p in AB exhibited a down-regulated pattern than NOM tissues (27). Studies have demonstrated that it is down-regulated in a variety of tumors, which plays a role in inhibiting tumor cell proliferation as well as invasion $(26,28)$. Intriguingly, it can also influence the biological behavior of tumors by targeting and regulating autophagy-related molecules. In NSCLC, miRNA-1 binds to ATG3 to inhibit ATG3mediated autophagy, thereby improving the cisplatin resistance of NSCLC cells (16). Through bioinformatics analysis, miR$1-3 p$ might be an upstream regulatory molecule of LAMP2. The negative correlation between the expression of miR-1-3p and LAMP2 was found in $\mathrm{AB}$. We found that there were miR-1-3p target sites within the $3^{\prime}$-UTR of LAMP2. Dual luciferase report confirmed that miR-1-3p could mediate LAMP2 expression by binding to the $3^{\prime}$-UTR of LAMP2. After validation, in $A B$ cells, miR-1-3p up-regulation significantly suppressed LAMP2 expression at the mRNA and protein levels. Also, miR1-3p restrained proliferation, migration and invasion of $A B$ cells through down-regulating LAMP2. Several animal trials have reported the use of $\mathrm{miR}-1-3 \mathrm{p}$ as a target for cancer intervention or treatment. For instance, miR-1-3p may inhibit xenograft tumor growth of lung adenocarcinoma (29). MiR-1$3 p$ up-regulation restrains hepatocellular carcinoma growth in mouse xenograft model (30). MiR-1-3p may overcome gefitinib resistance of lung cancer in tumor xenografts (31). In the formation and progression of tumors, lysosomes can increase the invasiveness of tumor cells by altering localization, volume, and composition, and releasing lysosomal enzymes (32, 33). LAMP2 mediates the fusion of autophagosomes and lysosomes during autophagy and plays an important role in autophagosome maturation (34). In colon cancer, LAMP2 is differentially expressed and has specific diagnostic value in the early stage of colon cancer as a molecular marker (35). In breast cancer, high

\section{REFERENCES}

1. Siar $\mathrm{CH}, \mathrm{Ng} \mathrm{KH}$. Epithelial-to-mesenchymal transition in ameloblastoma: focus on morphologically evident mesenchymal phenotypic transition. Pathology. (2019) 51:494-501. doi: 10.1016/j.pathol.2019. 04.004 expression of LAMP2 is also detected, and its high expression is significantly associated with tumor progression (36). In our research, LAMP2 was significantly up-regulated in AB tissues as well as epithelial-derived AM-1 cells, indicating that there could be an increase in autophagy activation in AB. LAMP2 upregulation promoted colony formation, migrated and invasive abilities of AB cells. Our further study showed that LAMP2 was significantly negatively correlated with miR-1-3p in $A B$, suggesting that miR-1-3p may regulate autophagy by inhibiting LAMP2 expression at post-transcriptional levels in AB, thereby participating in $\mathrm{AB}$ progression.

\section{CONCLUSION}

In our study, we examined the abnormal expression of autophagy-related proteins including LAMP2, Beclin1, and LC3, suggesting the activation of autophagy in AB. Further study showed that LAMP2 might be a potential target mRNA of miR-1$3 p$ in AB. MiR-1-3p silenced LAMP2 expression by binding to the 3'-UTR of LAMP2, thereby suppressing malignant phenotypes of $\mathrm{AB}$. Thus, our research may provide a novel insight into the mechanisms of $\mathrm{AB}$.

\section{DATA AVAILABILITY STATEMENT}

The original contributions presented in the study are included in the article/supplementary material, further inquiries can be directed to the corresponding author/s.

\section{ETHICS STATEMENT}

The studies involving human participants were reviewed and approved by the Ethics Committee of School and Hospital of Stomatology, China Medical University (2016-12). The patients/participants provided their written informed consent to participate in this study.

\section{AUTHOR CONTRIBUTIONS}

$\mathrm{MZ}$ conceived and designed the study. $\mathrm{XN}$ and $\mathrm{BH}$ conducted most of the experiments and data analysis, and wrote the manuscript. XQ, JL, and LC participated in collecting data and helped to draft the manuscript. All authors contributed to the article and approved the submitted version.

\section{FUNDING}

This work was funded by National Natural Science Foundation of China (81072197, 81470758). 
4. Hendra FN, Natsir Kalla DS, Van Cann EM, de Vet HCW, Helder $\mathrm{MN}$, Forouzanfar T. Radical vs. conservative treatment of intraosseous ameloblastoma: systematic review and meta-analysis. Oral Dis. (2018) 25:1683-96. doi: 10.1111/odi.13014

5. Onorati AV, Dyczynski M, Ojha R, Amaravadi RK. Targeting autophagy in cancer. Cancer. (2018) 124:3307-18. doi: 10.1002/cncr.31335

6. Poillet-Perez L, Xie X, Zhan L, Yang Y, Sharp DW, Hu ZS, et al. Autophagy maintains tumour growth through circulating arginine. Nature. (2018) 563:569-73. doi: 10.1038/s41586-018-0697-7

7. Sharp RC, Effiom OA, Dhingra A, Odukoya O, Olawuyi A, Arotiba GT, et al. Enhanced basal autophagy supports ameloblastomaderived cell survival and reactivation. Arch Oral Biol. (2019) 98:61-7. doi: 10.1016/j.archoralbio.2018.11.013

8. Xin X, Wu M, Meng Q, Wang C, Lu Y, Yang Y, et al. Long noncoding RNA HULC accelerates liver cancer by inhibiting PTEN via autophagy cooperation to miR15a. Mol Cancer. (2018) 17:94. doi: 10.1186/s12943-018-0843-8

9. Pajares M, Rojo AI, Arias E, Diaz-Carretero A, Cuervo AM, Cuadrado A. Transcription factor NFE2L2/NRF2 modulates chaperone-mediated autophagy through the regulation of LAMP2A. Autophagy. (2018) 14:131022. doi: 10.1080/15548627.2018.1474992

10. Hayes J, Peruzzi PP, Lawler S. MicroRNAs in cancer: biomarkers, functions and therapy. Trends Mol Med. (2014) 20:4609. doi: 10.1016/j.molmed.2014.06.005

11. Lu TX, Rothenberg ME. MicroRNA. J Allergy Clin Immunol. (2018) 141:12027. doi: 10.1016/j.jaci.2017.08.034

12. Rupaimoole R, Slack FJ. MicroRNA therapeutics: towards a new era for the management of cancer and other diseases. Nat Rev Drug Discov. (2017) 16:203-22. doi: 10.1038/nrd.2016.246

13. Sun L, Hu L, Cogdell D, Lu L, Gao C, Tian W, et al. MIR506 induces autophagy-related cell death in pancreatic cancer cells by targeting the STAT3 pathway. Autophagy. (2017) 13:703-14. doi: 10.1080/15548627.2017.1280217

14. Zhang X, Li Z, Xuan Z, Xu P, Wang W, Chen Z, et al. Novel role of miR-133a-3p in repressing gastric cancer growth and metastasis via blocking autophagy-mediated glutaminolysis. J Exp Clin Cancer Res. (2018) 37:320. doi: 10.1186/s13046-018-0993-y

15. Zhu H, Gan X, Jiang X, Diao S, Wu H, Hu J. ALKBH5 inhibited autophagy of epithelial ovarian cancer through miR-7 and BCL-2.J Exp Clin Cancer Res. (2019) 38:163. doi: 10.1186/s13046-019-1159-2

16. Hua L, Zhu G, Wei J. MicroRNA-1 overexpression increases chemosensitivity of non-small cell lung cancer cells by inhibiting autophagy related 3-mediated autophagy. Cell Biol Int. (2018) 42:1240-9. doi: 10.1002/cbin.10995

17. Kim JY, Kim J, Bazarsad S, Cha IH, Cho SW, Kim J. Bcl-2 is a prognostic marker and its silencing inhibits recurrence in ameloblastomas. Oral Dis. (2019) 25:1158-68. doi: 10.1111/odi.13070

18. Cha YH, Cho ES, Kang HE, Ko J, Nam W, Kim HJ, et al. Frequent oncogenic BRAF V600E mutation in odontogenic keratocyst. Oral Oncol. (2017) 74:627. doi: 10.1016/j.oraloncology.2017.09.016

19. Kurppa KJ, Caton J, Morgan PR, Ristimaki A, Ruhin B, Kellokoski J, et al. High frequency of BRAF V600E mutations in ameloblastoma. J Pathol. (2014) 232:492-8. doi: 10.1002/path.4317

20. Fregnani ER, Perez DE, Paes de Almeida O, Fonseca FP, Soares FA, CastroJunior G, et al. BRAF-V600E expression correlates with ameloblastoma aggressiveness. Histopathology. (2017) 70:473-84. doi: 10.1111/his.13095

21. Jiang C, Zhang Q, Shanti RM, Shi S, Chang TH, Carrasco L, et al. Mesenchymal stromal cell-derived interleukin-6 promotes epithelialmesenchymal transition and acquisition of epithelial stem-like cell properties in ameloblastoma epithelial cells. Stem Cells. (2017) 35:2083-94. doi: 10.1002/stem.2666

22. Huang F, Wang BR, Wang YG. Role of autophagy in tumorigenesis, metastasis, targeted therapy and drug resistance of hepatocellular carcinoma. World J Gastroenterol. (2018) 24:4643-51. doi: 10.3748/wjg.v24.i41.4643
23. Tong H, Yin H, Hossain MA, Wang Y, Wu F, Dong X, et al. Starvation-induced autophagy promotes the invasion and migration of human bladder cancer cells via TGF-beta1/Smad3-mediated epithelial-mesenchymal transition activation. J Cell Biochem. (2019) 120:5118-27. doi: 10.1002/jcb.27788

24. Kurioka K, Wato M, Iseki T, Tanaka A, Morita S. Differential expression of the epithelial mesenchymal transition factors snail, slug, twist, TGFbeta, and E-cadherin in ameloblastoma. Med Mol Morphol. (2017) 50:6875. doi: 10.1007/s00795-016-0149-0

25. Patsa S, Jadav RB, Halder GC, Ray JG, Datta S, Deb T. Demographic and histopathological variation of ameloblastoma: a hospital-based study. J Oral Maxillofac Pathol. (2016) 20:230-3. doi: 10.4103/0973-029X.185937

26. Antonoglou GN, Sandor GK. Recurrence rates of intraosseous ameloblastomas of the jaws: a systematic review of conservative versus aggressive treatment approaches and meta-analysis of non-randomized studies. J Craniomaxillo Fac Surg. (2015) 43:149-57. doi: 10.1016/j.jcms.2014.10.027

27. Chen L, Wang G, Qiao X, Wang X, Liu J, Niu X, et al. Downregulated miR524-5p participates in the tumor microenvironment of ameloblastoma by targeting the interleukin-33 (IL-33)/suppression of tumorigenicity 2 (ST2) axis. Med Sci Monit. (2020) 26:e921863. doi: 10.12659/MSM.921863

28. Wu L, Wang T, He D, Li X, Jiang Y. miR-1 inhibits the proliferation of breast cancer stem cells by targeting EVI-1. Onco Targets Ther. (2018) 11:877381. doi: 10.2147/OTT.S188836

29. Li T, Wang X, Jing L, Li Y. MiR-1-3p inhibits lung adenocarcinoma cell tumorigenesis via targeting protein regulator of cytokinesis 1. Front Oncol. (2019) 9:120. doi: 10.3389/fonc.2019.00120

30. Zhang H, Zhang Z, Gao L, Qiao Z, Yu M, Yu B, et al. miR-1-3p suppresses proliferation of hepatocellular carcinoma through targeting SOX9. Onco Targets Ther. (2019) 12:2149-57. doi: 10.2147/OTT.S197326

31. Jiao D, Chen J, Li Y, Tang X, Wang J, Xu W, et al. miR-1-3p and miR-206 sensitizes HGF-induced gefitinib-resistant human lung cancer cells through inhibition of c-Met signalling and EMT. J Cell Mol Med. (2018) 22:352636. doi: $10.1111 / \mathrm{jcmm} .13629$

32. Ngabire D, Kim GD. Autophagy and inflammatory response in the tumor microenvironment. Int J Mol Sci. (2017) 18:2016. doi: 10.3390/ijms18092016

33. $\mathrm{Pu} \mathrm{J,} \mathrm{Guardia} \mathrm{CM,} \mathrm{Keren-Kaplan} \mathrm{T,} \mathrm{Bonifacino} \mathrm{JS.} \mathrm{Mechanisms}$ and functions of lysosome positioning. J Cell Sci. (2016) 129:4329-39. doi: 10.1242/jcs. 196287

34. Hubert V, Peschel A, Langer B, Groger M, Rees A, Kain R. LAMP-2 is required for incorporating syntaxin-17 into autophagosomes and for their fusion with lysosomes. Biol Open. (2016) 5:1516-29. doi: 10.1242/bio.018648

35. Janikowska G, Janikowski T, Pyka-Pajak A, Mazurek U, Janikowski M, Gonciarz M, et al. Potential biomarkers for the early diagnosis of colorectal adenocarcinoma - transcriptomic analysis of four clinical stages. Cancer Biomark. (2018) 22:89-99. doi: 10.3233/CBM-170984

36. Damaghi M, Tafreshi NK, Lloyd MC, Sprung R, Estrella V, Wojtkowiak JW, et al. Chronic acidosis in the tumour microenvironment selects for overexpression of LAMP2 in the plasma membrane. Nat Commun. (2015) 6:8752. doi: $10.1038 /$ ncomms 9752

Conflict of Interest: The authors declare that the research was conducted in the absence of any commercial or financial relationships that could be construed as a potential conflict of interest.

Copyright (c) 2021 Niu, Huang, Qiao, Liu, Chen and Zhong. This is an open-access article distributed under the terms of the Creative Commons Attribution License (CC $B Y)$. The use, distribution or reproduction in other forums is permitted, provided the original author(s) and the copyright owner(s) are credited and that the original publication in this journal is cited, in accordance with accepted academic practice. No use, distribution or reproduction is permitted which does not comply with these terms. 